\title{
Noise Pollution and Health Effects
}

\author{
Sahar Geravandi ${ }^{1}$; Afshin Takdastan ${ }^{2}$; Elahe Zallaghi ${ }^{3}$; Mehdi Vousoghi Niri ${ }^{4}$; Mohammad \\ Javad Mohammadi ${ }^{4,} ;$ Hamed Saki $^{4}$; Abolfazl Naiemabadi ${ }^{4}$ \\ ${ }_{2}^{1}$ Department of Nursing, Tehran Medical Sciences Branch, Islamic Azad University, Tehran, IR Iran \\ ${ }^{2}$ Environmental Technologies Research Center, Department of Environmental Health Engineering, Health Faculty, Ahvaz Jundishapur University of Medical Sciences, Ahvaz, IR Iran \\ ${ }^{3}$ Department of Environmental, Khouzestan Sciences and Research, Islamic Azad University, Ahvaz, IR Iran \\ ${ }^{4}$ Department of Environmental Health Engineering, Health Faculty, Ahvaz Jundishapur University of Medical Sciences, Ahvaz, IR Iran \\ *Corresponding author: Mohammad Javad Mohammadi, Department of Environmental Health Engineering, Health Faculty, Ahvaz Jundishapur University of Medical Sciences, Ah- \\ vaz, IR Iran. Tel:+98-9355439707, E-mail: javad_sam2000@yahoo.com, Mohamadi.m@ajums.ac.ir
}

Received: November 15, 2014; Revised: December 21, 2014; Accepted: January 6, 2015

\begin{abstract}
Background: Noise pollution is of particular importance due to the physical and psychological effects on humans. Noise is a stressor that affects the autonomic nervous system and the endocrine system. Noise is also a threat to marine and terrestrial ecosystems. Health risks from noise are correlated with road traffic. In other words, noise health effects are the health consequences of elevated sound levels. Objectives: This study aims to determine the effect of noise pollution (near roadways) on health issues in Ahvaz, Iran.

Materials and Methods: In this cross-sectional study, equivalent sound pressure level were measured by sound level meters TES-1353 in 75 locations around 4 roadways, which had a high load of traffic in Ahvaz City during day time. During the study, 820 measurements were recorded at measuring stations, for 7 days per week with 1-hour interval between each measurement. Statistical analysis was carried out by SPSS software.

Results: According to the research findings, the equivalent sound pressure levels in all stations were $76.28 \pm 3.12 \mathrm{~dB}$ (Mean \pm SD). According to sound measurements and the survey questionnaire, noise pollution is higher than EPA(US Environmental Protection Agency) and Iran standard level. Based on result of this study the worst noise health effects were the nervousness and sleep quality during 2012.

Conclusions: According to the results of this study, with increasing load of traffic, there is an increasing need for proper consideration plans to control noise pollution and prevent its effects.
\end{abstract}

Keywords:Noise; Health Impact Assessment; Sound

\section{Background}

Living in megacities has brought many problems for its residents. In recent years, fast growing industry and vehicle population in the towns have resulted in considerable increase in traffic causing alarming noise and air pollution. Among the problems that can endanger human peace and health is noise pollution (1-4). Noise is also a threat to marine and terrestrial ecosystems. Noise health effects are the consequences of elevated sound levels (5). Exposure to road traffic noise is an important environmental problem that may cause hazardous effects in communities (6-8).

Epidemiological studies have reported the association between many medical problems such as myocardial infarction; cardiovascular disease; hypertension; sleep quality; mental disorders; immune system and birth defects; and exposure to road traffic noise; however, the correlations between noise frequency characteristics are not clear (9-16). Hypertension, increase secretion of adrenaline hormone, and heart rate are the most important complications of loud noises $(17,18)$. Noise level increases with traffic volume in an exponential rate. Aircrafts, mo- tor vehicles, subway and other transportation systems are significant sources of city noise (17).

Study results showed that noise pollution affects inhabitants of the megacities worldwide. The social costs of traffic noise in EU22 (European Union of 22 member states) are more than $€ 40$ billion peryear; passenger cars and lorries are responsible for the bulk of costs (19). According to the report of European Environment Agency, about 100 million persons are exposed to road traffic noise above 55 $\mathrm{dB}$ in European Union countries (20). Furthermore, it is believed that more than 200 million people worldwide are subject to the effects of noise (17). A study in California demonstrated that noise was increasing at the rate of 6.7 dBA due to street traffic (21). Rahmani et al. studied the association between noise levels and developed two noise determinants in 2011 (22). In a similar work, Lee et al. assessed road traffic noise levels and estimated the human exposure in Seoul, Korea (23). Another study to evaluate noise level in Curitiba, Brazil showed that people who live or work nearby these roads, experience above standard noise levels (24). In megacities like Ahvaz, complications 
from loud noises are one of the major factors hindering the comfort of the residents.

Ahvaz, the capital of Khuzestan Province with a population of approximately 1 million, and an area of $8152 \mathrm{~km}^{2}$ is located between $48^{\circ}$ and $49^{\circ} 29^{\prime}$ east of Greenwich meridian and between $31^{\circ} 45^{\prime}$ and the north of the equator (25-27). Since a long time ago, Ahvaz has been well known because of its industries as well as environmental pollution. In the last decade, increased motor vehicles and transportation on roadways have contributed to other environmental problems (25-28). Physical and psychological effects of loud noises have been well documented (25-28). Furthermore, study about health effects of noise pollution in most megacities, particularly Ahvaz is important. Therefore, we decided to assess health effects of noise pollution, which has not been studied yet $(1,21)$.

\section{Objectives}

The main purpose of this research was to assess the noise pollution and health effects near roadways in Ahvaz City in 2012.

\section{Materials and Methods}

This cross-sectional study was conducted in Ahvaz to assess noise index on 4 roadways (Ayatollah-Behbahani, Pasdaran, Azadegan, and Golestan) in 75 test locations in year 2012. In seeking to measure noise levels, the highest traffic load on the main streets was targeted that happens between 07:00 and 22:00. Next, 31 test locations were selected around the streets with the highest levels of traffic (Figure 1). Noise levels were measured using by a sound level meters TES-1353 with an analyzer, which was accurate and made based on international standards.
This device was calibrated before and after use based on stretcher international standards $(29,30)$. Sound level meters were placed at a height of $150 \mathrm{~cm}$ above the ground. Equivalent noise sampling was taken at 1-h intervals. The tests were performed from08:00 to 20:00, in all 75 test locations. Measurements in study locations were performed near the roadways $(29,31)$.

Samplings were done during week $(1,6,31)$. In the next step, we prepared questionnaires, which included items regarding the demographic characteristics and attitude of residents living near test locations about noise pollution effects, including myocardial infarction, depression, hypertension, sleep quality, mental health, decrease in hearing and nervousness. We used Cranach $\alpha(0.88)$ for determining validity and reliability of the questionnaire. The collected data were calculated and processed by Excel and SPSS (version 16). To analyze the data, we applied descriptive statistics, including frequency, percentage, and mean $( \pm S D)$. The primary standard of sound pressure according to EPA (US Environmental Protection Agency) is $65 \mathrm{~dB}$ (32). The standard of sound pressure level according to the standards of Iran Ministry of Health is $65 \mathrm{~dB}$ too (32) (Figure 2).

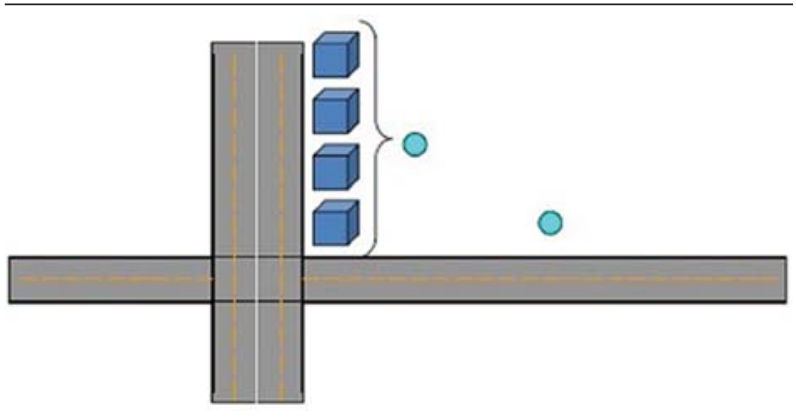

Figure 1. Study Locations in Near Roadway

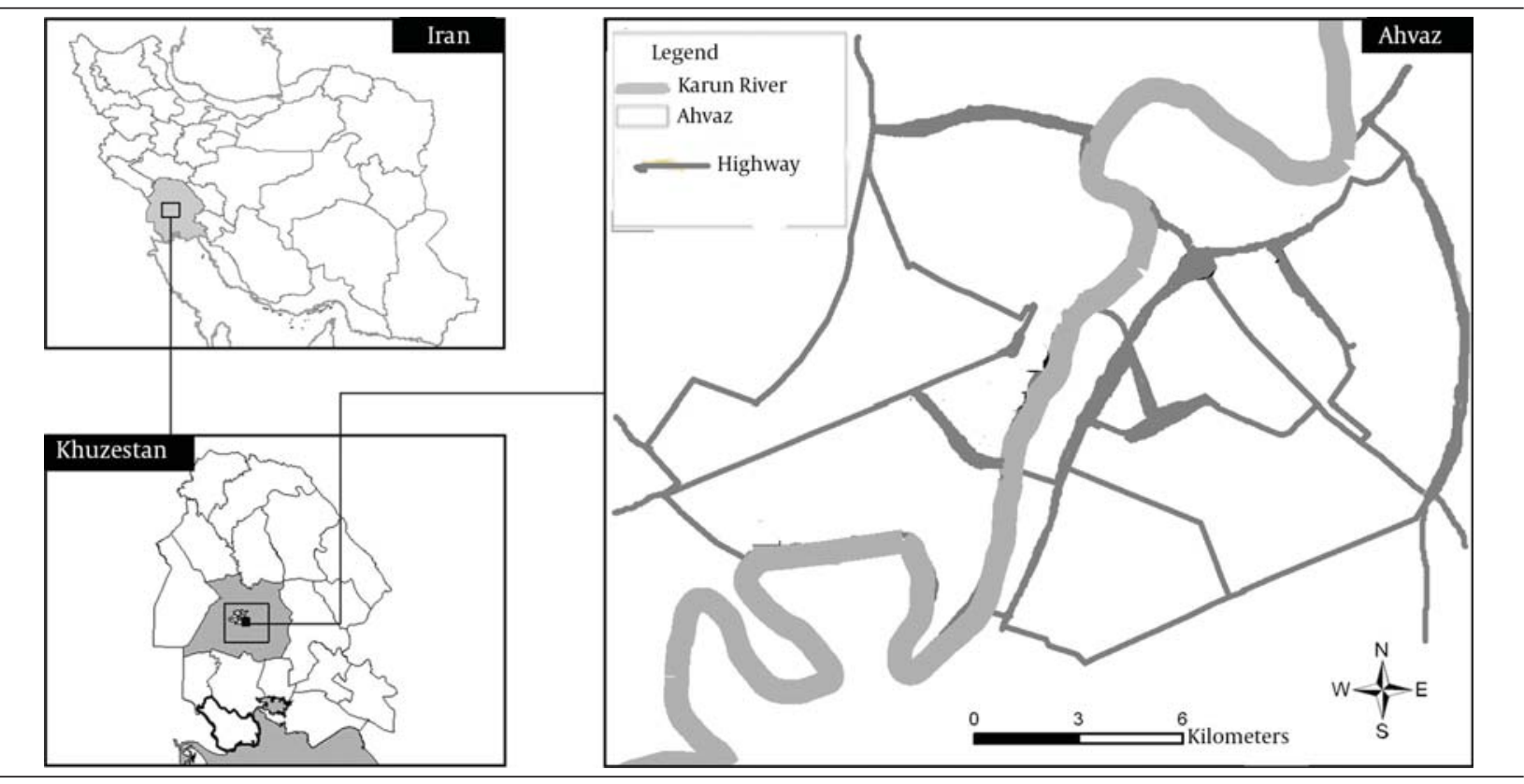

Figure 2. Location of the Study Area and Sampling Station in Ahvaz, Khuzestan Province, South-West of Iran 
Table 1. $\mathrm{L}_{\max }, \mathrm{L}_{\min }$ and $\mathrm{L}_{\mathrm{eq}}$ Measured Near Roadwaysin Ahvaz City, During $2012^{\mathrm{a}}$

\begin{tabular}{lccc}
\hline \multirow{2}{*}{ Estimate } & \multicolumn{3}{c}{ Parameter } \\
\cline { 2 - 4 } & $\mathbf{L}_{\mathrm{eq}}(\mathbf{d B})$ & $\mathbf{L}_{\min }(\mathbf{d B})$ & $\mathbf{L}_{\mathrm{max}}(\mathbf{d B})$ \\
\hline Minimum & 61.21 & 57.25 & 69.12 \\
Maximum & 91.35 & 80.62 & 95.46 \\
Mean & 76.28 & 68.93 & 84.32 \\
\hline a ${ }_{\text {Lmax }}:$ Maximum sound Pressure Level, $\mathrm{L}_{\text {min }}$ : Minimum sound \\
Pressure Level, $\mathrm{L}_{\mathrm{eq}}$ : Sound pressure Level.
\end{tabular}

Table 2. Main Health Effects Attributed to Noise Pollution Near Roadways in Ahvaz City, During 2012

\begin{tabular}{lc}
\hline Health Effects & Attitude Participants, No.(\%) \\
\hline Myocardial infarction & $11(3.66)$ \\
\hline Depression & $14(4.66)$ \\
Sleep quality & $51(17)$ \\
Decrease in hearing & $46(15.33)$ \\
Mental health & $31(10.33)$ \\
Hypertension & $23(7.66)$ \\
Nervousness & $124(41.33)$ \\
\hline
\end{tabular}

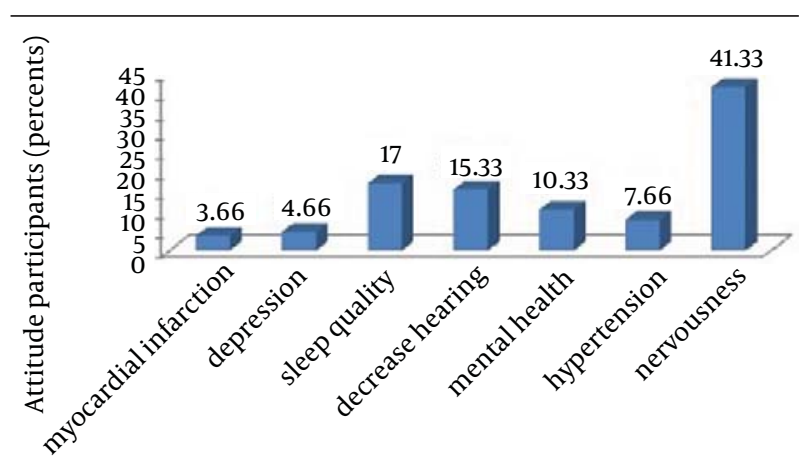

health effects attributed to noise pollution

Figure 3. Health Effects Caused by Noise Reported by Subjects in Ahvaz City During 2012

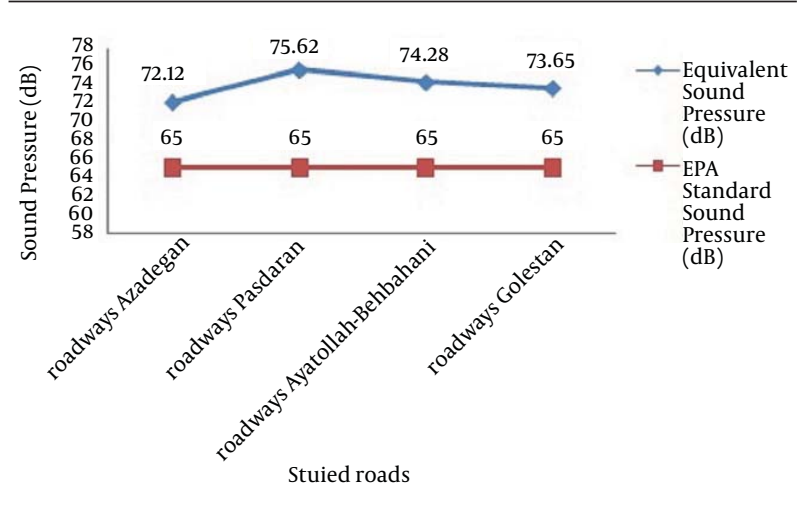

Figure 4. Relationship Between Standard Noise Pollution and Average Noise Pollution Measured in Roadway in Ahvaz City During 2012

\section{Results}

Based on the results of this study, almost all participants believed that noise pollution affects humans. Results showed that approximately $70 \%$ of the participants were male, and the mean age was $35.6 \pm 10.21 \mathrm{y}$. The results showed that approximately $85 \%$ of the measurements were higher than international standards. Also in this study, average sound pressure Level in all stations was $76.28 \pm 3.08 \mathrm{~dB}$, which was higher than EPA and Iran standard (65 dB) (Table 1) (32). The Pasdaran and Azadegan highways had the highest and the lowest equivalent sound pressure levels, respectively during 2012. Noise pollution parameters of the present study are shown in Tables 1 and 2, Figures 3 and 4. According to the findings in Table 2, nervousness, sleep quality, hypertension, decrease in hearing, mental health, depression, and myocardial infarction were the main health effects caused by the noise.

Figure 3 shows the health effects caused by noise reported by subjects in terms of the frequency of complications. Figure 4 shows that average measured noise pollution in roadways in Ahvaz City (during 2012) was higher than EPA and also much higher than Iran standards In view of noise pollution measured, shows that average roadway Pasdaran was the highest value in compare another roadways during this year, respectively.

\section{Discussion}

According to the findings (including sound measurements and the survey questionnaire), noise pollution near roadways in Ahvaz is higher than EPA and Iran standard level. Minimum and Maximum sound pressure levels were $84.32 \pm 4.07 \mathrm{~dB}$ and $68.93 \pm 4.14 \mathrm{~dB}$, respectively. Based on the results of this study, $41.33 \%$ of nervousness was attributed to traffic noise. Also, $17 \%$ of disturbance in sleep quality was attributed to traffic noise too. High percentage of the observed health endpoints was associated with high level of measured sound.

Some studies reported similar equivalent levels for traffic noise range. A meta-analysis of 14 studies on the association between road traffic noise and coronary heart diseases was carried out. Based on the result, Rahmani et al. showed noise level above standard in Iran (22). According to the study of Mirzaei et al. in Zahedan, approximately $62 \%$ of subjects reported that street noise was painful and nervousness is the main complication of the noise (17). Mirzaei showed that high and very high levels of noise have a negative effect on the feelings of tranquility (66.5\%) and sleep (66\%). High percentages of the observed health endpoints caused by noise in this study were associated with high measure sound pressure levels of noise in Ahvaz. One study on the effects of long-term exposure to road traffic noise on sleep quality, using questionnaires and actimetry, showed that sleep quality is most affected by noise levels (33).

Results of this study are different from with that of 
Ohrsrom study with respect to the geographic, demographic, and climate characteristics. In a research conducted in Kashan (Iran), the equivalent sound pressure level in high traffic points of the city was $81.7 \mathrm{~dB} 15$ (34). Based on the results of our study, maximum sound pressure level was relatively higher because of greater measured sound pressure levels in Ahvaz. In a research conducted in Sanandaj (Iran), the equivalent level at some hours of the day was $85 \mathrm{~dB}$ (35). Study of Hume et al. (2012) support evidence that night-time noise is likely associated with cardiovascular disease and stroke in the elderly. In this study, the result of myocardial infarction caused by noise is consistent with Hume study. In another study, Gan et al. showed that living within $50 \mathrm{~m}$ of a highway in metropolitan Vancouver was associated with $50 \%$ increase in the risk of coronary heart disease (12). Based on the results of our study, loud noise has effects on myocardial infarction similar to Gan study. One cross-sectional study has found a higher but non-significant prevalence of hypertension among male workers exposed to loud noises (36). The results of this study show that nervousness is associated with loud noise in Ahvaz. A study conducted in Messina, Italy showed $\mathrm{L}_{\mathrm{eq}}$ above $75 \mathrm{~dB}$ (37). The results this study shows that measured sound pressure levels in Ahvaz are very high compared to Italy.

Based on the results of this study and because of increasing traffic load and city population as well as noise pollution studies in other countries, there is an increasing need for proper involvement of traffic police and other relevant organizations to attend to this form of pollution. Although the results of this study are in line with results of other researches around the world, our geographic, demographic, and climate characteristics are different and further studies are really needed. By increasing knowledge and awareness among residents regarding the effects of noise pollution, a preventive solution may be achieved that decreases periods of noise pollution exposure. Because of the increasing trends of city population and traffic loads on roadway, there is a need for traffic management, using noise controllers, increased knowledge, planting barriers on both sides of the roads to absorb noise, using high speed reducers and community participation.

\section{Acknowledgements}

The authors would like to thank Azma Jonob Company for the technical support and providing the facilities.

\section{Authors' Contributions}

Study concept, design, and critical revision of the manuscript for important intellectual content: Mohammad Javad Mohammadi, Sahar Geravandi, Elahe Zallaghi, Afshin Takdastan, Hamed Saki, and Abolfazl Naiemabadi; Drafting of the manuscript and advisor: Mehdi Vosoughi; Conducting experiments: Elahe Zallaghi.

\section{Funding/Support}

This study was financially supported by Ahvaz Jundishapur University of Medical Sciences.

\section{References}

1. Data Acquisition Methods for Estimate the Noise Generated by the Road Traffic. In: Florea D, Cofaru C, Covaciu D, Timar J editors. . 3rd WSEAS Conference on Urban Planning and Transportation UPT. 2010 .

2. Kephalopoulos S, Paviotti M, Anfosso-Ledee F, Van Maercke D, Shilton S, Jones N. Advances in the development of common noise assessment methods in Europe: The CNOSSOS-EU framework for strategic environmental noise mapping. Sci Total Environ. 2014;482-483:400-10.

3. Sogebi OA, Amoran OE, Iyaniwura CA, Oyewole EA. Awareness and attitudes to noise and its hazards in motor parks in a suburban Nigerian town. Niger Postgrad Med J. 2014;21(1):40-5.

4. Harris DA. Noise Control Manual for Residential Buildings.New York: MC Graw Hill; 1997.

5. Maschke C. Stress Hormone Changes in Persons exposed to Simulated Night Noise. Noise Health. 2003;5(17):35-45.

6. Naddafi K, Yunesian M, Mesdaghinia AR, Mahvi AH, Asgari A. Noise Pollution in Zanjan City in 2007. ZUMSJ.2008;16(62):85-96.

7. Sarnat JA, Golan R, Greenwald R, Raysoni AU, Kewada P, Winquist $\mathrm{A}$, et al. Exposure to traffic pollution, acute inflammation and autonomic response in a panel of car commuters. Environ Res. 2014;133:66-76.

8. Sorensen M, Luhdorf P, Ketzel M, Andersen ZJ, Tjonneland A, Overvad K, et al. Combined effects of road traffic noise and ambient air pollution in relation to risk for stroke? Environ Res. 2014;133:49-55.

9. Banerjee D. Association between transportation noise and cardiovascular disease: a meta-analysis of cross-sectional studies among adult populations from 1980 to 2010. Indian J Public Health. 2014;58(2):84-91.

10. Leon Bluhm G, Berglind N, Nordling E, Rosenlund M. Road traffic noise and hypertension. Occup Environ Med. 2007;64(2):122-6.

11. Chang TY, Beelen R, Li SF, Chen TI, Lin YJ, Bao BY, et al. Road traffic noise frequency and prevalent hypertension in Taichung, Taiwan: a cross-sectional study. Environ Health. 2014;13(1):37.

12. Gan WQ, Tamburic L, Davies HW, Demers PA, Koehoorn M, Brauer $M$. Changes in residential proximity to road traffic and the risk of death from coronary heart disease. Epidemiology. 2010;21(5):642-9.

13. Istamto $\mathrm{T}$, Houthuijs D, Lebret E. Multi-country willingness to pay study on road-traffic environmental health effects: are people willing and able to provide a number? Environ Health. 2014;13(1):35.

14. Selander J, Bluhm G, Nilsson M, Hallqvist J, Theorell T, Willix P, et al. Joint effects of job strain and road-traffic and occupational noise on myocardial infarction. Scand J Work Environ Health. 2013;39(2):195-203.

15. Sorensen M, Andersen ZI, Nordsborg RB, Jensen SS, Lillelund KG, Beelen R, et al. Road traffic noise and incident myocardial infarction: a prospective cohort study. PLoS One. 2012;7(6).

16. Sygna K, Aasvang GM, Aamodt G, Oftedal B, Krog NH. Road traffic noise, sleep and mental health. Environ Res. 2014;131:17-24.

17. Mirzaei R, Ansari-Mogaddam A, Mohammadi M, Rakhshani F, Salmanpor M. Noise Pollution in Zahedan and Residents' Knowledge About Noise Pollution. Health Scope. 2012;1(1):3-6.

18. Powazka EE. A cross-sectional study of occupational noise exposure and blood pressure in steelworkers. Noise Health. 2003;5(17):15-22.

19. den Boer LC, Schroten A. Traffic noise reduction in Europe. 2008 Available from: http://www.transportenvironment.org/sites/te/ files/media/2008-02_traffic_noise_ce_delft_report.pdf.

20. Roosli M. [Health effects of environmental noise exposure]. Ther Umsch. 2013;70(12):720-4.

21. Gündogdu O, Gokdag M, Yuksel F. A traffic noise prediction method based on vehicle composition using genetic algorithms. Appl Acoust. 2005;66(7):799-809. 
22. Rahmani S, Mousavi SM, Kamali MJ. Modeling of road-traffic noise with the use of genetic algorithm. Appl Soft Comput. 2011;11(1):1008-13.

23. Lee J, Gu J, Park H, Yun H, Kim S, Lee W, et al. Estimation of populations exposed to road traffic noise in districts of Seoul metropolitan area of Korea. Int JEnviron Res Public Health. 2014;11(3):2729-40.

24. Calixto A, Diniz FB, Zannin PHT. The statistical modeling of road traffic noise in an urban setting. Cities. 2003;20(1):23-9.

25. Geravandi S, Mohammadi MJ, Goudarzi G, Ahmadi Angali K, Neisi AK, Zalaghi E. Health effects of exposure to particulate matter less than 10 microns (PM10) in Ahvaz. J Qazvin Univ Med Sci. 2014;18(5):45-53.

26. Goudarzi G, Geravandi S, Vosoughi M, Mohammadi M, Neisi A, Taghavirad SS. Cardiovascular deaths related to Carbon monoxide Exposure in Ahvaz, Iran. 2014. 2014;1(3):6.

27. Goudarzi G, Mohammadi MJ, Ahmadi Angali K, Neisi AK, Babaei AA, Mohammadi B, et al. Estimation of Health Effects Attributed to NO2 Exposure Using AirQ Model. Arch Hyg Sci. 2011;1(2).

28. Taghavirad SS, Mohammadi MJ. The a study on concentration of betx vapors during winter in the department of ports and shipping located in one of the southern cities of iran. Int J Current Life Sci. 2014;4(9):5416-20.

29. Fidell S. Nationwide urban noise survey. J Acoust Soc Am. 1978;
64(1):198-215.

30. Golmohammadi R, Aliabadi M. Noise Pollution and its Irritating Effects in Hospitals of Hamadan, Iran. J Health System Res. 2012;7(6):958-64.

31. Wetzel E, Nicolas J, Andre P, Boreux JJ. Modelling the propagation pathway of street-traffic noise: practical comparison of German guidelines and real-world measurements. Appl Acoust. 1999;57(2):97-107.

32. Kayvani N. National Environmental Protection Organization. 1st edTehran: Dayereh sabz; 2004.

33. Ohrstrom E. Sleep Studies Before and After - Results and Comparison of Different Methods. Noise Health. 2002;4(15):65-7.

34. Motallebi Kashani M, Hannani M, Akbari H, Almasi H. Noise Pollution Survey in Kashan City (2000-2001). Feyz J. 2002;6(1):30-6.

35. Reshadmanesh N, Shariat M, Imandel K. Evaluation of the environmental health in Sanandaj. J Kordestan Univ Med Sci . 1996;1(2):16-20.

36. Chang TY, Liu CS, Young LH, Wang VS, Jian SE, Bao BY. Noise frequency components and the prevalence of hypertension in workers. Sci Total Environ. 2012;416:89-96.

37. Piccolo A, Plutino D, Cannistraro G. Evaluation and analysis of the environmental noise of Messina, Italy. Applied Acoustics. 2005;66(4):447-65. 